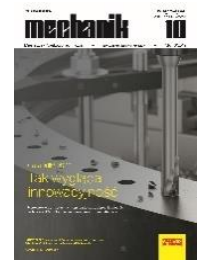

How to cite this article:

Authors: Sebastian Sdzuj, Łukasz Winchula

Title of article: „Stages of designing and making a pressing tool for gutter corner halves with a complicated shape. The

milling methods used."

Mechanik, No. 10 (2019)

DOI: https://doi.org/10.17814/mechanik.2019.10.83

\title{
Stages of designing and making a pressing tool for gutter corner halves with a complicated shape. The milling methods used.
}

\author{
SEBASTIAN SDZUJ \\ ŁUKASZ WINCHULA *
}

Inż. Sebastian Sdzuj, sebastian.sdzuj@protec.pl - PROTEC, Chróścice, Polska

Inż. Łukasz Winchula, lukasz.winchula@protec.pl - PROTEC, Chróścice, Polska

Design features were described, applied in order to adapt complicated parts of a pressing tool to the capabilities of a 3-axis vertical machining center. The design and selection of base surfaces making possible precise positioning in the milling machine and in the tool are discussed.

KEYWORDS: CAD design, CAM, CNC milling, positioning in milling machine, pressing tool, welding of sheet metal

\section{Introduction}

As part of the project entitled "R\&D works on the development of a new technology for joining gutter system components with complex shapes from titanium-zinc sheets using the welding process", a process of connecting two gutter corner halves by welding was prepared. First, the halves were designed so that along the entire length of the weld in the shape of an ellipse arc (fig. 1) there was an $1.7 \mathrm{~mm}$ wide overlap with full contact (fig. 2), keeping the same layout pattern of $0.7 \mathrm{~mm}$ thick sheet metal for both different halves. Dimensions of $\sim 4$ $\mathrm{mm}$ define the boundaries of the pressing zone, beyond which the cross-section of the corner maintains constant.

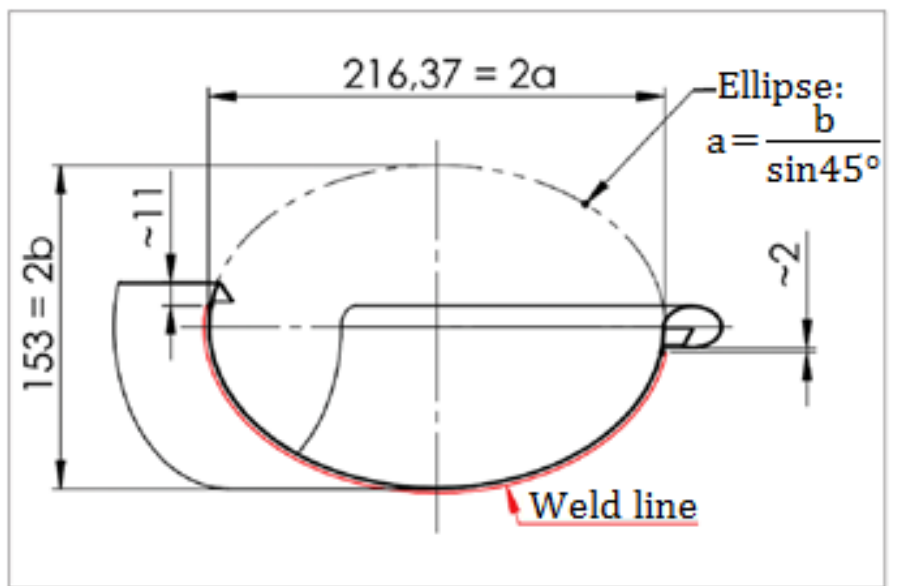

Fig. 1. The course of the weld bead against the background of the cross-section of the welded profile 


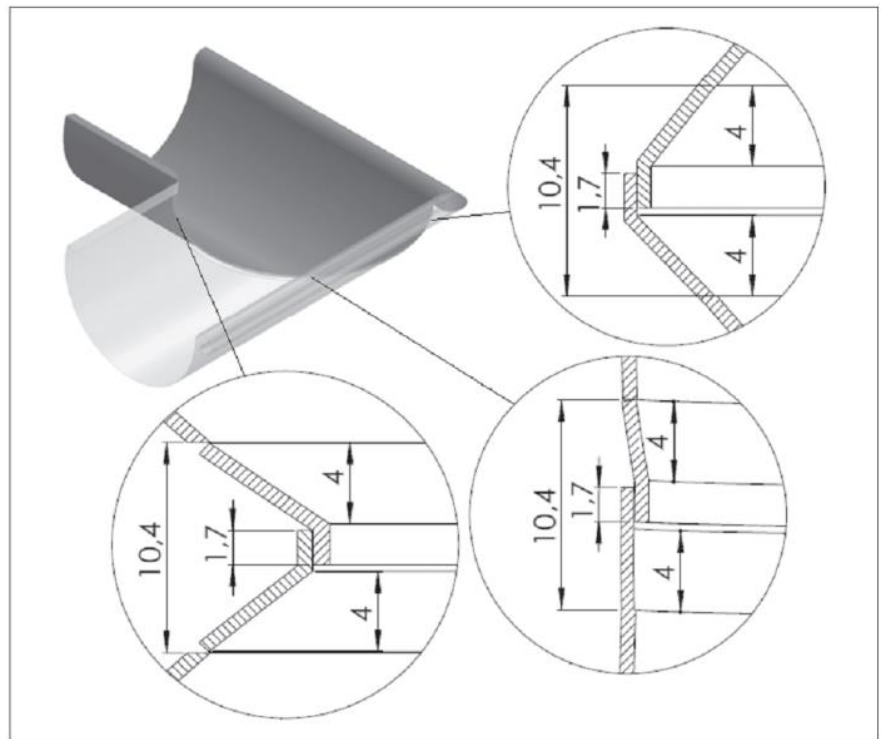

Fig. 2. Overlap and pressing area in the course of the weld

While developing the process of forming the corner halves (fig. 2), it was decided to manufacture the tooling components on our in-house machinery. The tools have been designed so that it is possible to produce e.g. stamps and dies without using machines such as a five-axis machining center or wire EDM.

\section{Significance of selected milling methods in the instrument production process}

Designing the tools for shaping metal sheets depends on the possibility of shaping the elements that make up the tool. In order to reduce costs and simplify the control of the die production process, an attempt was made to limit machining to a vertical three-axis center and auxiliary machines for roughing and surface grinding. The difficulty was to meet a variety of criteria, e.g.

- the area of forming the corner halves exceeds $180^{\circ}$ around the main axis of the gutter, therefore it is not possible to shape the corner halves with one stamp and one matrix;

- corner elements must be made precisely, since deviations from the planned shape may disturb the correct positioning of the corner halves in the welding device;

- during welding, the laps must match to each other along the entire length of the elliptical weld.

Based on previously used welding techniques, it was concluded that the loss of contact between the halves during welding causes a bad weld [1]. Additional conditions are:

- the matrix must be divided into at least two parts with an independent path of movement, because otherwise it is not possible to insert a stamp into it,

- the stamp should be divided in such a way that the modification of the shape after subsequent tests does not require finish machining of large areas.

\section{Design and milling tools}

All solids were designed in the SOLIDWORKS program. Programs for machining the three-dimensional shapes were created in the SOLIDCAM program.

First, preparations were made based on the drawings. Then, with the help of G code files and drawings, further processing steps were carried out.

Rough milling was carried out with standard heads and cylindrical cutters for roughing. During finishing milling of three-dimensional surfaces, cylindrical cutters with a radius at the corner were used.

All finishing operations were performed by constant z-axis or linear machining, in which the cutter carries out successive parallel lines with a given pitch.

\section{Construction optimization}

The milling process of the die (fig. 3) is not special, because the entire finish milling was performed in one fixing. 


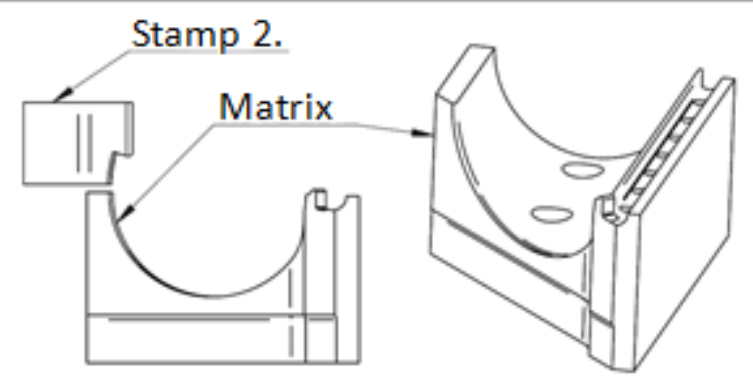

Fig. 3. Elements of the device shaping the overlap from the outside

In the case of stamps (fig. 4), it turned out necessary to give them design features that enable milling in two positions and at a selected angle. The essence of developing shapes was to minimize the number of bases for different clamping without losing the possibility of precise positioning on the machine.

The first stamp shapes most of the overlap from the inside. It consists of a body positioning the gutter profile (fig. 5) and a shaping plate (fig. 6).

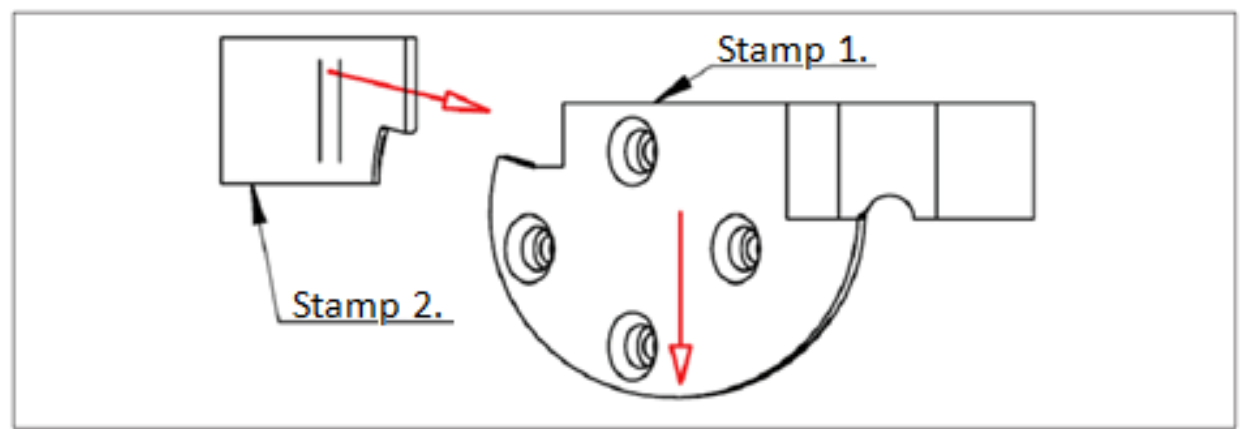

Fig. 4. Stamp 1 and stamp 2 with marked directions of work in the device

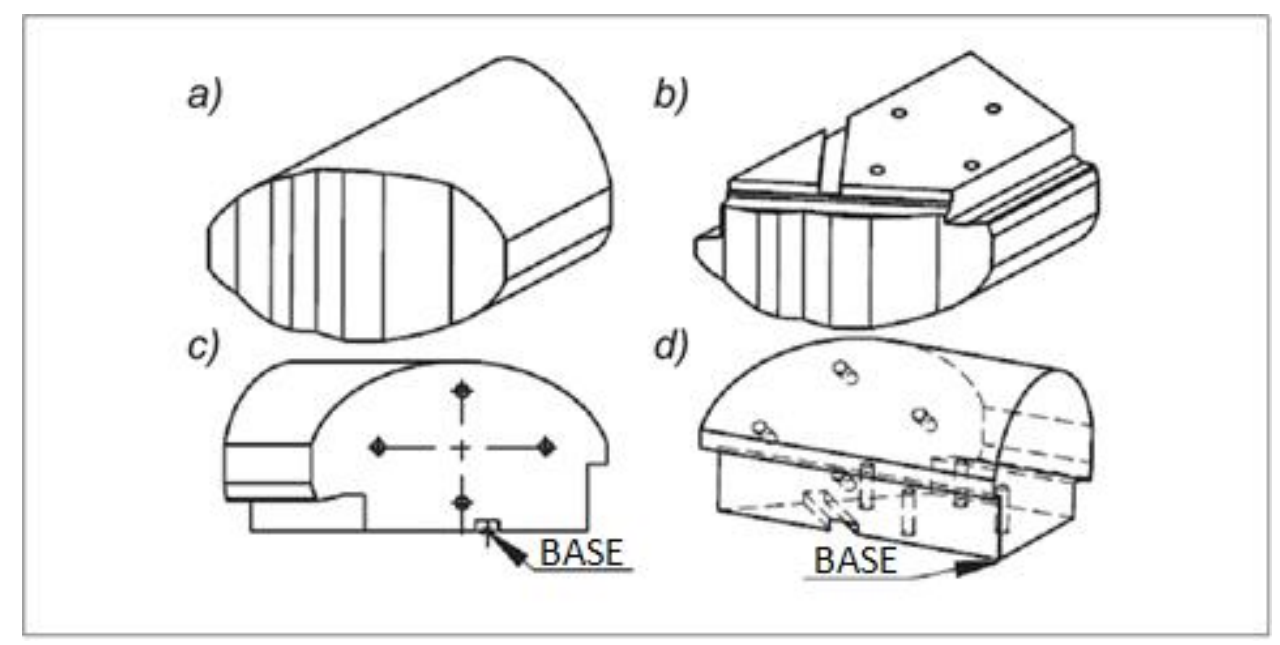

Fig. 5. Positioning body of the punch 1 at various stages of execution: $a$ ) preparation, $b$ ) after milling in the first mounting, $c$ ) after planning and drilling in the second mounting, $d$ ) after milling in the third mounting

The preparation (fig. $5 a$ ) was made of a bar by turning to the appropriate diameter with leaving allowance, planning of the planes allowing for mounting the block in a vice and cutting at an angle of $45^{\circ}$ to obtain the second piece.

During the first machining (fig. $5 b$ ) carried out using CAM software, a basing groove (obliquely to the cylinder axis), a plane with threaded holes, vertical planes around the base of the stamp and a part of the positioning surfaces were made. In the next fastening (fig. $5 c$ ), the mounting plane was planned and threaded holes were made. The previously mentioned groove together with the vertical wall was used for homing. In the last fixing (fig. 5d), most of the positioning surface was finished. To shape the welding lap, the shaping attachment of the stamp 1 screwed to the body (fig. 6) was used. The blank (fig. $6 a$ ) was made with the precise position of the planes and holes relative to the base. Next, roughing and finishing of shaping surfaces were carried out in two fastenings. For positioning, four chamfered holes were used, placed on precise sleeves. 


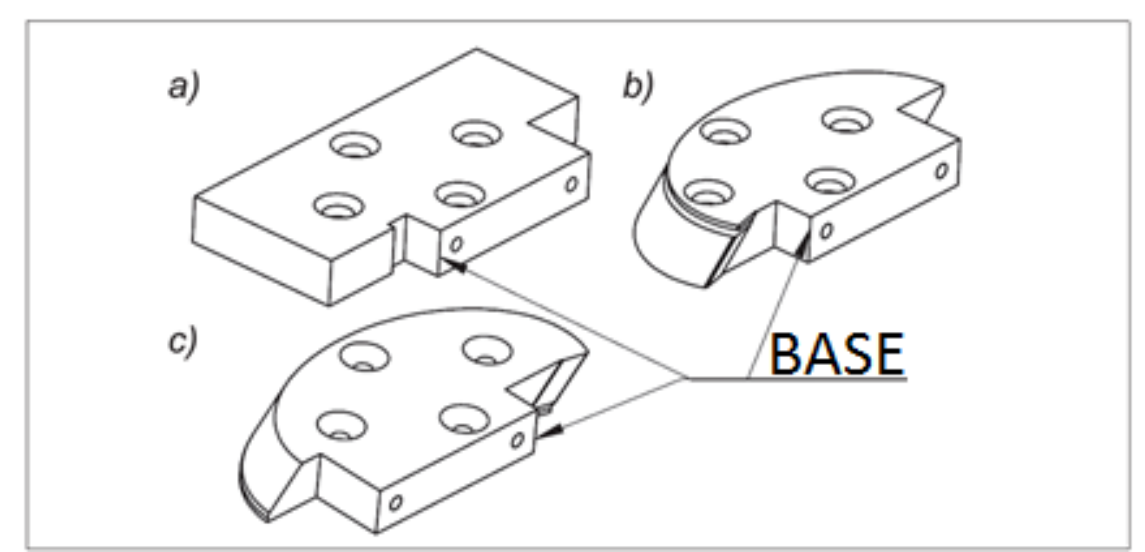

Fig. 6. Shaping insert of stamp 1: a) preparation, $b$ ) and $c$ ) in subsequent positions during machining with the help of the CAM program

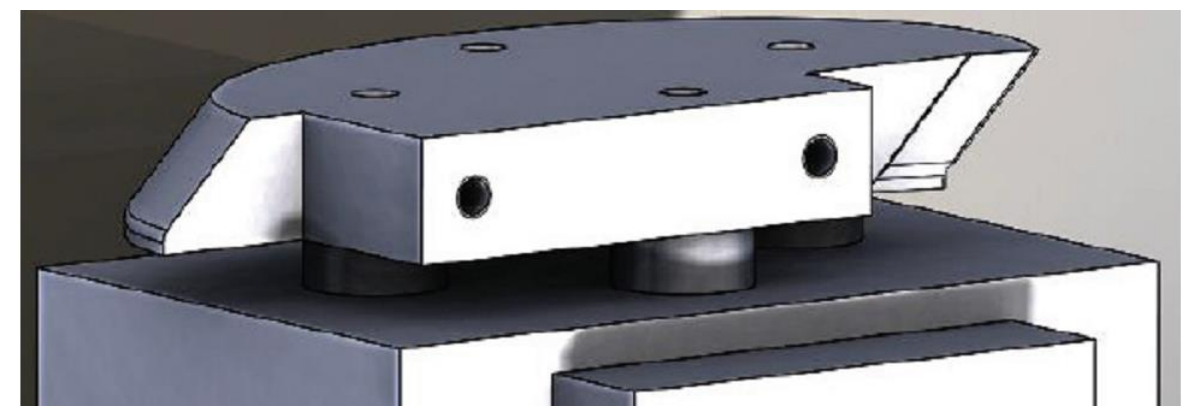

Fig. 7. Stamp 1 shaping insert based on bushes with chamfers, fixed with screws to the plate in a vice

The stamp 2. moves in the device at an angle of $13.9^{\circ}$ (fig. 4) and completes the role of a matrix, which itself can work only in the area of $180^{\circ}$. The weld on the finished product also takes place in the connection point of the die and stamp 2. If a fault occurred as a result of their application, and as a result the overlap would not adhere, it could cause insufficient weld quality in this place. This results in the need for precise execution of the stamp 2.

The shape of the stamp 2. requires milling from a blank positioned at an angle of $17^{\circ}$ to the horizontal. First, a protrusion for angular homing and a groove were milled on a rectangular preparation with precisely derived angles (fig. 8a). The projection has planes for homing in three axes, while the groove is used to check the level. The blank prepared in such a way can be precisely positioned in the machine tool vice at an angle that allows access to the machined surfaces.

Figs. $8 b$ and Fig. 9 show the finished stamp 2 in positions used on the vertical machining center. The stamp produced in this way cannot only be placed in the device with high positioning accuracy, but also reprocessed if necessary to correct the shape.

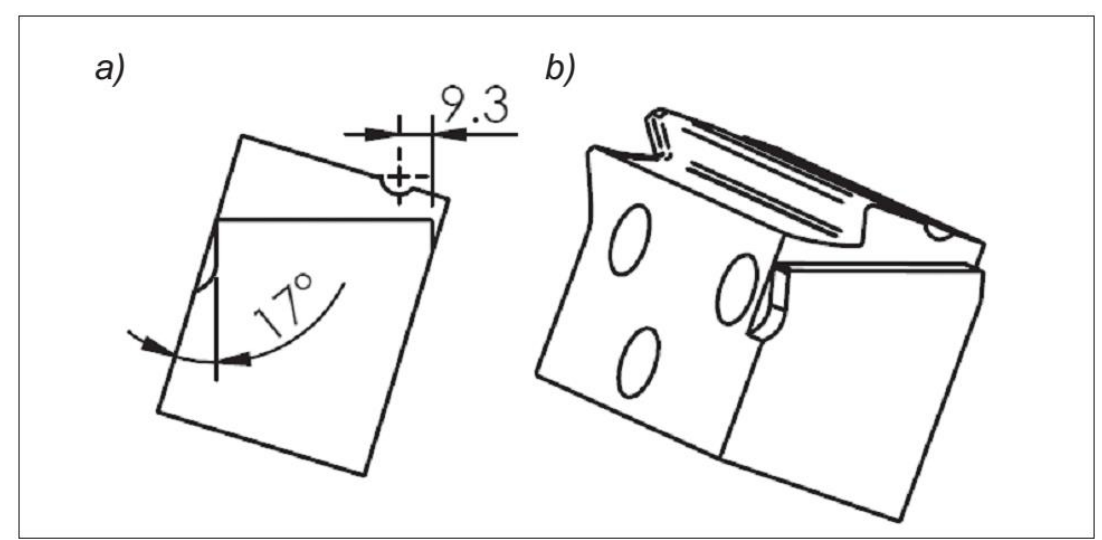

Fig. 8. Stamp 2 at various stages of manufacture: $a$ ) blank with base surfaces applied, $b$ ) final solid in the position used during the first machining 


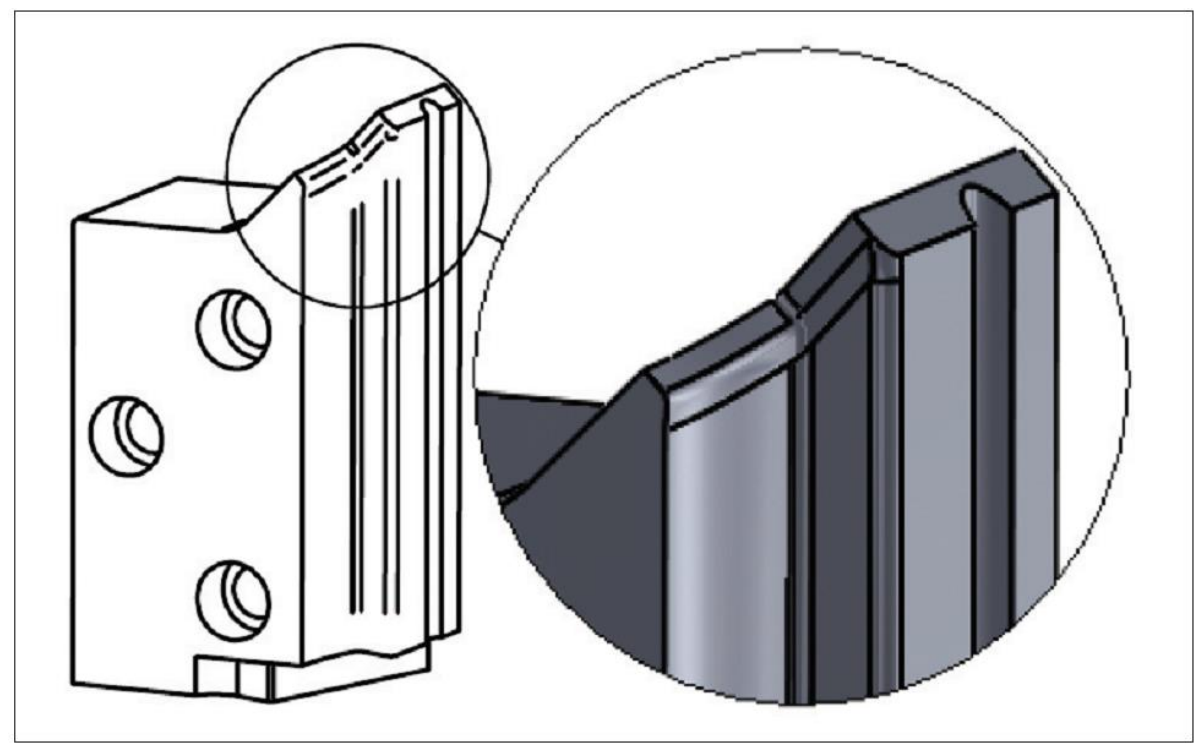

Fig. 9. Stamp 2 in the position used during the second machining

\section{Summary}

In fig. 10, there is a photo of the finished stamp 2. From the pressing side, it can be repeatedly modified and regenerated by successive changes or repeating the finishing treatment performed in the position shown in fig. 9. By distance in the device, the position of the forming part is restored. For the needs of trial corner halves, which are to be used to work out the correct sheet metal pattern and optimal welding lap, the components of the device were prepared as prototypes. They were made of steel grade 1.2379 in annealed condition. Based on previous experiments, it has been estimated that the results of milling work can be easily translated into machining of hardened parts after rough machining before quenching. Machining after hardening is necessary due to the expected durability of the tool while maintaining the exact shape of punches and dies during the production of large series.

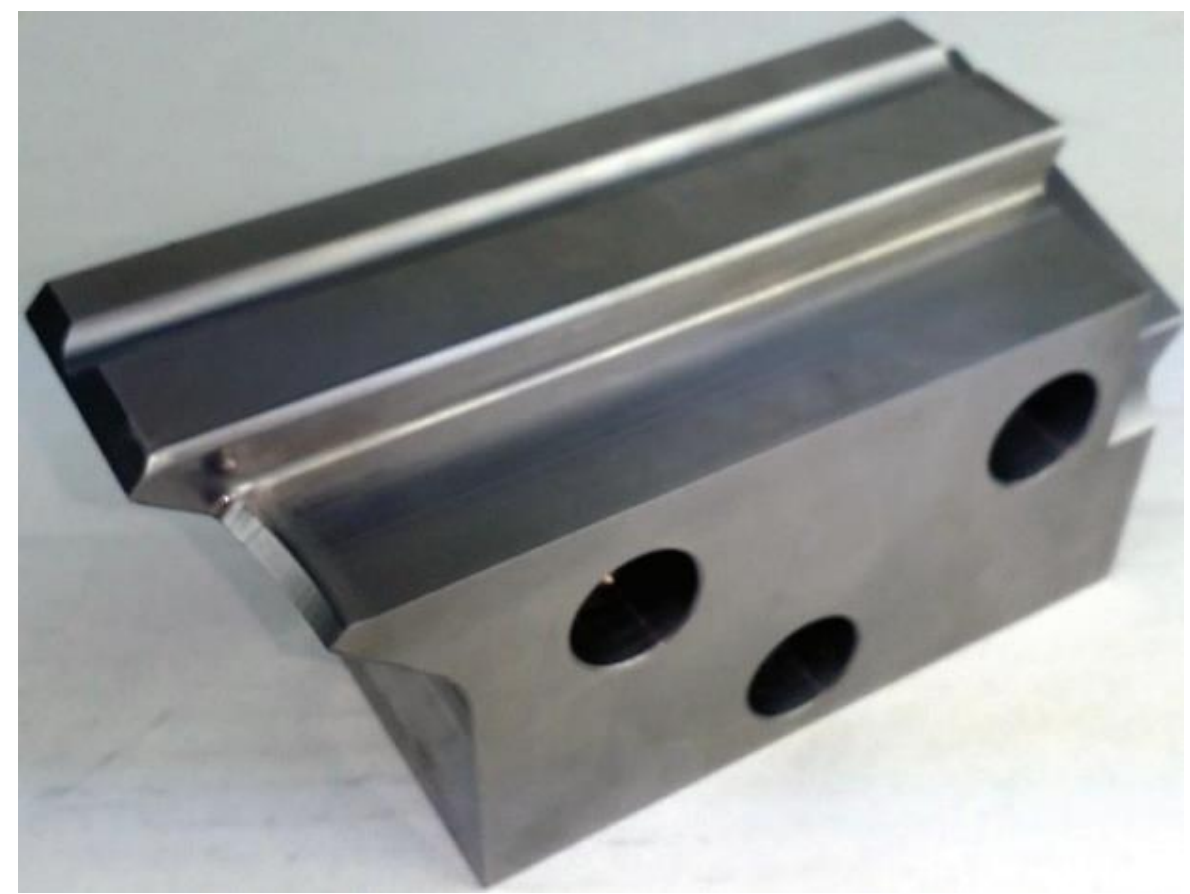

Fig. 10. Ready stamp 2

In fig. 11, there is a photo of an example of a weld. At the bottom left enlargement, there is not enough meltthrough. At the middle magnification, one can see a properly made weld. On the right, a fragment with too much melting is shown, which may origin from e.g. when the overlap is too small. Defects in the weld made in this way have various reasons, but the need for tight contact of the overlap applies to the entire length. 


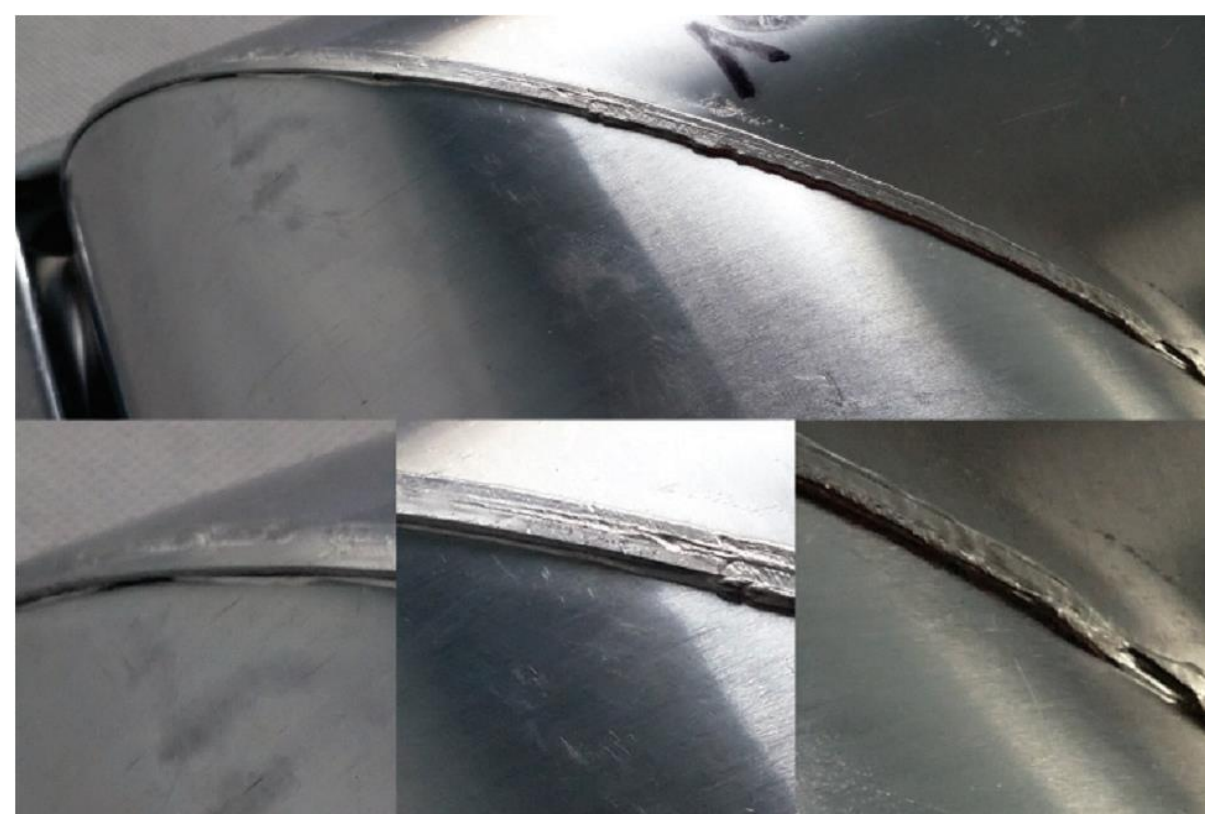

Fig. 11. Sample test weld with enlargement of selected areas

As a result of presented works, very carefully made components for the welding lap forming device were obtained. At the current stage of development of this welding technology, there are no contraindications to the further use of the techniques discussed. By adjusting the shapes of the stamps to the in-house manufacturing capabilities, the number of organizational activities associated with each shape change or repair has been significantly reduced.

\section{REFERENCES}

[1] Brol. S. et all. „The effects of gutter welding using mechatronic device utilizing complex kinematics”. Zeszyty Naukowe Instytutu Pojazdów. 2 (2019): 11-17. 